\title{
Brazilian Society of Cardiology - The Women's Letter
}

\author{
*Endorsed by European Society of Cardiology (ESC)
}

Glaucia Maria Moraes de Oliveira, ${ }^{10}$ Fátima Elizabeth Fonseca de Oliveira Negri, ${ }^{2}$ Nadine Oliveira Clausell, ${ }^{3}$ Maria da Consolação V. Moreira, ${ }^{4}$ Olga Ferreira de Souza, ${ }^{5}$ Ariane Vieira Scarlatelli Macedo, ${ }^{4}$ Barbara Campos Abreu Marino, ${ }^{6}$ Carisi Anne Polanczyk, ${ }^{3}$ Carla Janice Baister Lantieri, ${ }^{7}$ Celi Marques-Santos, ${ }^{8}$ Cláudia Maria Vilas Freire, ${ }^{4}$ Deborah Christina Nercolini, ${ }^{9}$ Fatima Cristina Monteiro Pedroti, ${ }^{10}$ Imara Correia de Queiroz Barbosa, ${ }^{11}$ Magaly Arrais dos Santos, ${ }^{12}$ Maria Christiane Valéria Braga Braile, ${ }^{13}$ Maria Sanali Moura de Oliveira Paiva, ${ }^{14}$ Marianna Deway Andrade Dracoulakis, ${ }^{15}$ Narriane Chaves Holanda, ${ }^{16}$ Patricia Toscano Rocha Rolim, ${ }^{17}$ Roberta Tavares Barreto Teixeira, ${ }^{2}$ Sandra Mattos, ${ }^{18}$ Sheyla Cristina Tonheiro Ferro da Silva, ${ }^{8}$ Simone Cristina Soares Brandão, ${ }^{19}$ Viviana de Mello Guzzo Lemke, ${ }^{20}$ Marcelo Antônio Cartaxo Queiroga Lopes ${ }^{21}$

Universidade Federal do Rio de Janeiro, ${ }^{1}$ Rio de Janeiro, $R J$ - Brazil

Hospital Universitário Lauro Wanderley - Universidade Federal da Paraíba, ${ }^{2}$ João Pessoa, PB - Brazil

Universidade Federal do Rio Grande do Sul, ${ }^{3}$ Porto Alegre, RS - Brazil

Faculdade de Medicina da Universidade Federal de Minas Gerais, ${ }^{4}$ Belo Horizonte, MG - Brazil

Rede D'OR São Luiz, ${ }^{5}$ Rio de Janeiro, $R J$ - Brazil

Hospital Madre Teresa, ${ }^{6}$ Belo Horizonte, MG - Brazil

Faculdade de Medicina do $A B C,{ }^{7}$ Santo André, SP - Brazil

Hospital São Lucas, ${ }^{8}$ Aracaju, SE - Brazil

Hospital das Clínicas da Universidade Federal do Paraná, ${ }^{9}$ Curitiba, PR - Brazil

Universidade Federal do Espirito Santo, ${ }^{10}$ Vitória, ES - Brazil

Universidade Federal de Campina Grande, ${ }^{11}$ Campina Grande, PB - Brazil

Hospital do Coração para Instituto Dante Pazzanese de Cardiologia, ${ }^{12}$ São Paulo, SP - Brasil

Instituto Domingo Braile, ${ }^{13}$ São José do Rio Preto, SP - Brazil

Hospital Universitário Onofre Lopes, ${ }^{14}$ Natal, $R N$ - Brazil

Instituição Ensino de Pesquisa do Hospital da Bahia, ${ }^{15}$ Salvador, BA - Brazil

Universidade Federal da Paraíba, ${ }^{16}$ João Pessoa, PB - Brazil

CENTROCOR, ${ }^{17}$ João Pessoa, PB - Brazil

Real Hospital Português de Beneficência em Pernambuco, ${ }^{18}$ Recife, PE - Brazil

Universidade Federal de Pernambuco, ${ }^{19}$ Recife, PE - Brazil

Cardiocare Clínica Cardiológica, ${ }^{20}$ Curitiba, PR - Brazil

Hospital Metropolitano Dom José Maria Pires, ${ }^{21}$ João Pessoa, PB - Brazil

\section{Objective}

The primary objective of this document is to stimulate improvements in women's health conditions in Brazil, with a focus on cardiovascular disease (CVD), which is responsible for 17.5 million premature deaths yearly worldwide. This number is predicted to increase to 23 million by 2030. CVD are responsible for one third of all deaths in Brazil, with similarities between men and postmenopausal women. These data assume even greater importance when we consider that $80 \%$ of premature deaths could have been avoided by controlling four risk factors: tobacco use, inappropriate diet, physical inactivity, and harmful alcohol use. ${ }^{1}$

\section{Keywords}

Women; Medicine/ trends; Demography; Cardiovascular Diseases/prevention and control; Societies, Medical; Management Quality Circles; Risk Factors; Prevalence; Education, Medical.

Mailing Address: Gláucia Maria Moraes de Oliveira •

Universidade Federal do Rio de Janeiro - R. Prof. Rodolpho P. Rocco, 255

$-8^{\circ}$. Andar - Sala 6, UFRJ. Postal Code 21941-913, Cidade Universitária,

RJ - Brazil

E-mail: glauciam@cardiol.br, glauciamoraesoliveira@gmail.com

Manuscript received May 03, 2019, revised manuscript May 15, 2019, accepted 15, 2019

DOI: $10.5935 / a b c .20190111$
This document further aims to create a permanent discussion group that will play a leadership role in Brazilian healthcare policies, providing administrators with an overall view of the relevance of CVD to women so that they may establish strategic actions to reduce the prevalence of risk factors and improve diagnosis and therapeutic approach, thus reducing mortality and morbidity.

\section{Foreword}

Considering that the burden of chronic noncommunicable diseases (CNCD), of which CVD are the main component, will continue to grow significantly in Brazil and worldwide; in line with the global target of a $25 \%$ reduction in premature mortality from noncommunicable diseases by 2025 as established by the World Health Assembly (WHA); ${ }^{2}$ and in accordance with the United Nations High-level Meeting on the Prevention and Control of Noncommunicable Diseases, we endorse the measures proposed by this Assembly which reunited the cardiology societies of the Rio de Janeiro Letter, ${ }^{3}$ also highlighting the importance of goals to be met for women, who currently represent $48 \%$ of the 7.7 billion inhabitants of the world and $47 \%$ of the $202,768,562$ individuals who compose the population of Brazil, as of April 2019. ${ }^{4}$

In recognition of the fact that, predominantly among younger doctors, the proportion of women doctors has increased over the past years, going from 22\% in 1910 to $45.6 \%$ in 2018 , and considering the fact that this increase 
has been less accelerated among women cardiologists, where women currently represent approximately $30 \%$ of the total, ${ }^{5}$ we highlight the importance of promoting activities whose aim is to multiply healthcare opportunities from women's point of view, allowing for the integration and exchange of experience which will amplify improvements in daily clinical practice.

Emphasizing that the presence of women in science today corresponds to $28 \%$ of researchers worldwide, according to UNESCO, and $49 \%$ in Brazil, ${ }^{6}$ with less than one quarter of speakers at scientific events being women, in addition to the low representation of women in clinical trials which determine therapies to be used, we propose that forums be held, wherein it will be possible to discuss cost-effective, short- and long-term measures to decrease these inequalities, as well as affirmative policies which may accelerate women's representation in science and clinical research.

In conclusion, knowing the relevance of the role which medical societies and their associates play as critical agents for paradigm change and the establishment of multiple partnerships, we call on these entities to be protagonists in the elaboration of documents which will act as tools to accelerate these results.

\section{Deliberations}

1. To work collectively to defend global goals for the prevention and control of CNCD, especially CVD, in Brazilian women.

2. To establish cardiovascular prevention campaigns, promoting efforts consistent with the global goal of $25 \%$ reduction in mortality rates by 2025 .

3. To perform critical analyses of health statistics and to implement registers capable of evaluating and measuring cardiovascular health issues, so that there may be improvements in strategic health actions.
4. To elaborate and suggest government policies to promote appropriate environments for reducing exposure to risks, facilitating the population's adoption of healthy habits in school, work, and leisure environments, with the aim of combating CVD in women.

5. To work and act together with governments for the development and application of cardiovascular prevention programs, in addition to incorporating cost-effective technologies to reduce CVD morbidity and mortality.

6. To involve patients with CVD and diverse segments of civil society in formulating, implementing, and reviewing policies, legislation, and discussion on strategies which may lead to improvements in women's healthcare.

7. To develop collaborative projects through scientific societies which may aggregate different forms of knowledge in order to reduce genders inequalities.

8. To provide the highest level of continuing medical education, to promote technical, scientific, cultural, and social exchanges between cardiologists in Brazil and worldwide, and to cultivate the scientific knowledge necessary to increase women's participation in science, scientific events, and health and related sciences.

9. To mobilize means of communication in order to bring continual information on the importance of CVD in women, as well as its primary risk factors and forms of prevention, thus amplifying the transmission of the importance of early diagnosis to the general population.

10. To create an international permanent discussion forum in order to monitor actions with the aim of preventing, diagnosing, and treating cardiovascular risk factors.

11. To stimulate actively the greater participation of women cardiologists in Executive Boards of Representative Bodies, so that they may have the same rights and remuneration in the diverse aspects of their medical careers.

\section{Erratum}

In special article "Heart Failure Awareness Day: A Tribute to the Genius Carlos Chagas", consider Maria Christiane Valéria Braga Braile as the correct form for the name of the author Maria Cristiane Valeria Braga Braile.

\section{References}

1. GBD 2017 Disease and Injury Incidence and Prevalence Collaborators. Global, regional, and national incidence, prevalence, and years lived with disability for 354 diseases and injuries for 195 countries and territories, 1990-2017: a systematic analysis for the Global Burden of Disease Study 2017. Lancet. 2018;392(10159):1789-858.

2. World Health Organization.(WHO). $65^{\text {th }}$ World Health Assembly document A65/54: Second report of Committee A, Netherlands 2012 May 25. [Cited in 2019 April 29]. Available from: http://apps.who.int/gb/ebwha/pdf_files/ WHA65/A65_54-en.pdf

3. Andrade JP, Arnett DK, Pinto FJ, Piñeiro D, Smith Jr SC, Mattos LAP, et al. Sociedade Brasileira de Cardiologia - Carta do Rio de Janeiro - III Brasil Prevent/ I América Latina Prevent. Arq Bras Cardiol. 2013;100(1):3-5.
4. Instituto Brasileiro de Geografia e Estatística.(IBGE). Projeção da população do Brasil e das Unidades da Federação [Internet [Acesso em 2019 abr 29]. Disponível em: https:/www.ibge.gov.br/apps/populacao/projecao/

5. Scheffer M, Cassenote A, Guilloux AGA, Miotto BA, Mainardi GM, Demografia Médica no Brasil 2018. São Paulo, SP: FMUSP, CFM, Cremesp; 2018. [Acesso em 2019 abr 29]. Disponível em: http://www.epsjv.fiocruz. br/sites/default/files/files/DemografiaMedica2018\%20(3).pdf

6. Engin K, Tran M, Connor R, Uhlenbrook S. The United Nations world water development report 2018: nature-based solutions for water; facts and figures. UNESCO; 2018. [Cited in 2019 April 29]. Available from: https:// unesdoc.unesco.org/ark:/48223/pf0000261579 